Inter-Regional Spillovers of Policy Shocks in China

by

Nicolaas Groenewold*

Economics Program,

University of Western Australia

Crawley, WA 6009

Australia

Anping Chen,

Department of Economics,

Jinan University,

Guangzhou, 510632

Guangdong Province,

China

and

Guoping Lee,

School of Economics and Finance,

$\mathrm{Xi}$ 'an Jiaotong University,

Xi'an, 710061

Shaanxi Province,

China

*Corresponding author: e-mail: nic.groenewold@uwa.edu.au, phone +61 86488 3345, fax +61864881016

We are grateful to the Department of International Co-operation at Xi'an Jiaotong

University and to the School of Economics and Commerce at the University of

Western Australia for grants which supported the visit of the first-named author to Xi'an. 


\title{
Inter-Regional Spillovers of Policy Shocks in China
}

\begin{abstract}
In China inter-regional per capita output disparities are large and persistent and increasingly a matter for policy concern at the highest levels of government. Interregional spillovers are an important ingredient in the design of regional development policy. Yet little is known about the direction, magnitude and timing of output spillovers from one region to another. In this paper we focus on spillovers from policy shocks. We use a conventional three-region disaggregation of the Chinese economy and extend existing literature by explicitly introducing policy variables into a VAR model of regional outputs. We find that both policy variables have significant and positive effects on output in each of the regions when entered separately. In the short run both policy variables have a greater effect on the coastal region than on the other two and the effect in the central region is larger than in the western region, giving some credence to the common presumption that at least part of the expenditure boosts in the poorer inland regions find their way to the coastal provinces. These results are generally confirmed when we use the whole model to simulate the effects over time of the policy shocks. A shock to the coastal region not only has no beneficial spillovers to the other regions but actually depresses the output of the inland provinces. This is also true of a shock to the central region which comes at the expense of the western region. Only the western region has consistent positive spillovers on the other regions; looked at another way, a boost to the western region is shifted partially to the other regions.
\end{abstract}

JEL codes: R11, R12 


\section{Introduction}

The phenomenal growth of China's economy over the past three decades or so is well known - growth in the 25 years since the beginning of economic reforms under Deng Xiaoping has averaged $9.5 \%$ per annum and is set to continue at about this rate for at least another decade according to informed commentators. This rapid growth has been far from smooth, however. Even over the relatively settled period after 1978, the growth rate has fluctuated between $3 \%$ and $15 \%$, with fluctuations even larger if we consider the experience of the pre-reform period.

Intertemporal fluctuations in growth is only one facet of the unevenness of China's growth experience - there have also been significant differences in the spatial distribution of growth and this has occurred in a number of dimensions. Two of the most important arise from the urban-rural distinction and the regional disaggregation of the country. In this paper we focus on the regional dimension with the regions based on aggregations of the provinces.

In the post-1978 period the average annual growth rate has varied from a low of $7.6 \%$ for Qinghai province in the north-west of China to rates over $13 \%$ for the south coastal provinces of Zhejiang, Fujian and Guangdong. Of greater concern than the differences in growth rates is the fact that, by and large, these differences have exacerbated already large disparities in per capita output levels. Thus in 2005 Qinghai had a per capita GDP of 10,030 yuan compared to that of Zhejiang of 27,369, Fujian of 18,613 and Guangdong of 23,674 . $^{1}$

Not surprisingly, the spatial distribution of economic activity and welfare has been the subject of considerable interest to both policy-makers and academic researchers. Policy-makers have regularly expressed concern about the adverse implications of regional disparities for national cohesion. Thus, for example, one of the key issues discussed in the context of the recent fifth plenary session of the $16^{\text {th }}$ Central Committee of the Communist Party was the gap between rich and poor regions which was seen as a major potential source of political instability in a country where the difficulty of holding the empire together has always been a central challenge for the political leadership.

Moreover, this has long been recognised. ${ }^{2}$ While the early Five-Year Plans focussed on industrialisation concentrating on the north-eastern provinces, from the mid- 
1960s the Five-Year Plans have regularly recognised the necessity to address the widening disparities in regional output, although policy responses have varied over time. Thus, a decade later in the Fifth Five-Year Plan (1976-1980) there was a shift of focus back to the coast and this policy of unbalanced growth was continued at least until the Seventh Five-Year Plan (1986-1990). This redirection of capital to the already fastgrowing coastal provinces was based on the argument that the scarce development resources of the country should be allocated to those regions likely to benefit most in terms of growth and the expectation that fast-growing coastal regions would act as a growth locomotive, taking the rest of the country with it (see Ying, 2000 for an elaboration and references on this point).

As already mentioned, more recent Plans have shifted the focus back towards the interior with growing concern about the implications for social instability of large and persistent differences in inter-provincial levels of economic welfare. This is evidenced by a number of special policies: the Great Western Experiment (announced in 1999 during the Ninth Five-Year Plan), the Resurgence of North-Eastern Old Industry Base and the Stimulation of the Central Region (both during the Tenth Five-year Plan) and the Eleventh Five-Year Plan in which there has been a major push to redress the growing regional disparities. It is not clear, however, whether the central government imagines this greater equality to be at the cost of a lower average growth rate.

This tension between overall economic development and increasing regional disparities is reminiscent of the distinction between "backwash" and "spread" effects discussed in the development literature of a generation ago (see, e.g., Myrdal, 1957, and Hirschman, 1958) and revived in the more recent "New Economic Geography" associated with Krugman and others (see, e.g., Krugman, 1991a, 1991b, Krugman and Venables, 1996, and Puga, 1999).

One of the crucial questions in both the policy debate and in the regional development literature is the nature of output or growth spillovers between regions. An explanation for the increasing inter-regional disparities accompanying Chinese economic growth in the post-1978 period is the absence of strong positive economic linkages between regions which would make the coastal region a locomotive for economic growth. 
While there has been much discussion of these inter-regional spillovers, there is remarkably little empirical work assessing their strength, direction and timing, notwithstanding the large empirical literature on Chinese regional economic growth. Indeed, there are, to our knowledge, only a handful of papers which directly address the question of regional spillovers in China - Ying (2000), Zhang and Felmingham (2002), Brun, Combes and Renard (2002), Fu (2004) and Groenewold, Lee and Chen (2005a, 2005b, 2006).

All these papers, however, limit their analysis to output spillovers with no thought as to how the output shock might be generated. From a policy perspective this would not be a limitation if all policy instruments generated the same initial output effects. There is no reason for this to be the case so that, before these papers can be taken as a starting point of policy formulation, a necessary extension of the existing literature is to introduce policy variables directly into the analysis to enable us to investigate the spillover effects of measures taken by policy-makers to boost output.

In this paper we make a beginning in this direction by introducing two alternative policy variables into the vector-autoregressive (VAR) model previously used by Groenewold, Lee and Chen (2005a, 2005b, 2006) and others. In particular, we extend a three-region VAR model by introducing a policy instrument for each region at a time as an exogenous variable, shocking the policy variable by a standard shock and examining the effects in all regions over time. We use two alternative policy instruments, government investment and government expenditure, and compare the effects of shocks to these across regions and across instruments.

The remainder of the paper is structured as follows. Section 2 provides a brief review of the relevant literature. Section 3 describes the data and includes a discussion of the definition of the regions. In section 4 we set out the VAR model and explain the process used for simulation on the basis of which we examine spillovers. The model estimation and simulations are reported in section 5. Our conclusions are presented in the final section. 


\section{Literature Review}

There is a rapidly growing literature on regional economic growth in China. Most of this literature is, however, concerned with long-run questions which are the traditional concern of growth theory. Thus much of the literature is cast in terms of the convergence debate which focuses on whether there are persistent disparities between regions (usually provinces in China), whether these disparities will disappear of their own accord (the convergence question) and, if not, what are the factors that determine the equilibrium disparities (the conditioning variables in conditional convergence). ${ }^{3}$

While most of the discussion of Chinese regional economic activity has been in the convergence framework, little has focussed on the short-term fluctuations in output and in particular on the interaction between regional output levels which is necessary to address the spillover issue identified in the first section as the focus of the present paper.

To our knowledge, only seven papers have explicitly examined inter-regional spillovers for China, generally using different methods of analysis. The first, by Ying (2000) used provincial output data and the "exploratory data analysis" technique to examine the relationships between the growth rate of a particular province and those near it. He found that the strongest significant influence was exerted by Guangdong province with which there were significant correlations with four of the five contiguous provinces although two were positive and two negative. However, his technique of spatial data analysis is essentially one of static growth correlations which is not suitable for our purposes which are to analyse the direction, strength and timing of spillovers between regions, all of which are necessarily dynamic questions.

The three papers by Brun, Combes and Renard (2002), Zhang and Felmingham (2002) and $\mathrm{Fu}$ (2004) all analyse inter-regional spillovers within a standard growth framework and as an aside to other questions - Brun et al. to the question of growth convergence and Zhang and Felmingham as well as $\mathrm{Fu}$ to the issue of relationship between exports, FDI and growth. They all find some evidence of spillovers from the coast to the inland regions, although weak evidence in the case of $\mathrm{Fu}$; Zhang and Felmingham's also find evidence of a positive effect of the coast on the west. However, in all cases their analysis is limited to testing the significance in growth equations of spillover proxies which they treat as exogenous, thus excluding the possibility of 
feedback between all regions and falling short of a thorough-going dynamic analysis of the interaction between the regions.

The final group of extant papers is by Groenewold, Lee and Chen (2005a, 2005b, 2006). The first of these uses annual data for three regions (conventionally defined as coastal, central and western) for the period 1953-2003 to estimate and simulate a vectorautoregressive (VAR) model. ${ }^{4}$ In that paper it is found that there are strong spillovers from the coastal region to both other regions, from the central region to the western region but that shocks to the western region have no flow-on effect for the other two regions. There are concerns, however, about the sensitivity of the result to the ordering of the variables, a problem that is inherent in many applications of the VAR model. This issue is addressed in Groenewold et al. (2006) where it is found that the main results survive alternative methods for dealing with this problem.

In Groenwold et al. (2005b) the authors extend the number of regions to six - the North East, Yellow River, Changjiang River, South East, South West and North West regions. There they also explicitly address the variable-ordering problem. They found, not surprisingly, that the Yellow River and Changjiang River regions had spillover effects although they were more extensive for the former; the South Western region had no significant spillovers effects on the rest of the country, consistently with other research results. However, in contrast to other research, shocks to the South East affect mainly the region itself with little spillover to the other regions while the North West region has general spillover effects.

In the present paper we contribute to the literature by explicitly introducing policy variables into the VAR model. In order to keep the analysis as simple as possible and to maintain comparability with the results in Groenewold et al. (2005a, 2006), we limit ourselves to the three-region model. 


\section{The Data}

We require data of two types - regional output data and data for the policy variables. We discuss each of them in turn. The output data used are recently available annual series on real provincial GDP for the period 1953-2003. ${ }^{5}$ The sources of the data are two-fold: the early data come from Wu (2004) who obtained the 1953-1995 series from China's GDP Data 1952-95 (State Statistical Bureau, 1997). Data for 1996-2002 come from the Statistical Yearbook of China (State Statistical Bureau, various years) and for 2003 from the China Statistical Abstract (State Statistical Bureau, 2004).

The second set of variables is the policy variables. We use two, the first is government investment and the second is general government expenditure. ${ }^{6}$ Both variables are available disaggregated by province. The sources of the data for the policy variables is as follows: for government investment expenditure for 1953-1995 we used Data and Materials on China's Capital Construction 1950-1995 (State Statistical Bureau, 1997) and for 1996-2003 we used the Statistical Yearbook of China (State Statistical Bureau, various years); for general government expenditure for 1953-1998 we used Comprehensive Statistical Data and Materials on 50 Years of New China (State Statistical Bureau, 2000) and for 1999-2003 we used the Statistical Yearbook of China (State Statistical Bureau, various years). Since neither capital construction nor expenditure deflators are available at the provincial level of disaggregation, we used the provincial GDP deflator to deflate the nominal investment and expenditure to get real policy variables for each province.

We use the provincial series to compute regional equivalents for real GDP and the policy variables. We aggregated the provinces into three regions conventionally defined as coastal, central and western regions. The composition of these three regions is as follows. Coastal: Beijing, Tianjin, Hebei, Guangdong, Shandong, Fujian, Zhejiang, Jiangsu, Shanghai, Liaoning, Guangxi; Central: Shanxi, Inner Mongolia, Jilin, Heilongjiang, Anhui, Jiangxi, Henan, Hubei, Hunan; Western: Sichuan, Guizhou, Yunnan, Shaanxi, Gansu, Qinghai, Ningxia, Xinjiang. ${ }^{7}$

Before proceeding to the estimation and simulation results we need to attend to a preliminary matter In empirical analysis based on time-series data it is customary to assess the stationarity of the data and to difference the data if non-stationary (unless the 
variables are cointegrated). Groenewold et al. (2005a) contains an exhaustive discussion of the stationarity of the (logs of) the regional real output series used here. They find that all three series are trend stationary if the trend is allowed to break at 1978 . There is also a possible break in trend at 1966 . We reproduce their main results for log real regional outputs as well as reporting new results for the regional policy variables. They are shown in Table 1. Clearly, all variables are stationary about trend if we allow for breaks at 1966 and 1978 and we can proceed, as they did, to specify the VAR model in terms of log levels as long as we include a trend and breaks.

\section{[Table 1 near here]}

\section{The VAR Model}

Like Groenewold et al. (2005a, 2005b, 2006), we use a vector-autoregressive (VAR) framework to explore the empirical relationship between the three regional output variables. We briefly set out the model here and refer the interested reader to their papers for a more detailed exposition and, in particular, an explanation of the "ordering problem" which, for reasons set out below, is not an issue in the current application.

For the general case in which there are $\mathrm{n}$ regions and $\mathrm{m}$ policy variables, the model to be estimated has the form:

$$
\boldsymbol{x}_{t}=\boldsymbol{a}_{0}+\boldsymbol{D} \mathbf{z}_{t}+\boldsymbol{A}(L) \boldsymbol{x}_{t-1}+\boldsymbol{e}_{t}
$$

where $\boldsymbol{x}$ is an n-component vector of regional outputs, $\boldsymbol{a}_{0}$ is an n-component vector of intercepts, $\boldsymbol{D}$ is an $(\mathrm{n} \times \mathrm{m})$ matrix of coefficients, $\mathbf{z}$ is an $\mathbf{m}$-component vector of exogenous policy variables, $\boldsymbol{A}(L)$ is a pth-order matrix polynomial in the lag operator, $L$, which is defined as $L^{r} \boldsymbol{x}_{t}=\boldsymbol{x}_{t-r}$ and $\boldsymbol{e}_{t}$ is an n-vector of random error terms.

Given the exogeneity assumption for the policy variables, the regressors in (1) are either exogenous or predetermined so that this system of equations can be validly estimated using OLS. The estimated model can then be used to simulate the effects on the regional output $x_{i}$, say, of a shock to policy variable $z_{j}$, say, for each period $\tau$. The resulting time path of $x$ for $\tau=0,1,2, \ldots$ is the impulse response function (IRF) for $x_{i}$ with respect to $z_{j}$ and can be computed from the moving average (MA) form of the model:

$$
\boldsymbol{x}_{t}=\boldsymbol{c}_{0}+\boldsymbol{F}(L) \mathbf{z}_{t}+\boldsymbol{C}(L) \boldsymbol{e}_{t}
$$


where $\boldsymbol{C}(L)=(\boldsymbol{I}-\boldsymbol{A}(L))^{-1}, \boldsymbol{c}_{0}=\boldsymbol{C}(L) \boldsymbol{a}, \boldsymbol{F}(L)=\boldsymbol{C}(L) \boldsymbol{D}$ and $\boldsymbol{I}$ is an $(\mathrm{n} \times \mathrm{n})$ identity matrix.

In most applications of the VAR model, it is the error terms which are shocked, something that requires the independence of these errors. The standard way of ensuring independence of the errors necessary for generating the IRFs introduces an arbitrary element into the analysis in that it makes the results dependent on the order in which the variables are entered in the VAR model, something which is usually difficult to determine a priori $^{8}$ This difficulty is treated at some length in the papers by Groenewold et al. but is avoided in the present application since we wish to simulate the effects of shocks to the exogenous variables which by their nature can be shocked independently of the errors and of each other. In this case the IRFs are simply the elements of the $\boldsymbol{F}$ matrices in equation (2). 


\section{Results}

We consider the effects of shocks to two alternative policy variables: government investment expenditure and general government expenditure. We analyse the effects of each separately and consider them in turn.

\subsection{Shocks to Government Investment Expenditure}

The model used to generate the IRFs is simply the three-region model reported in Groenewold et al. (2005a) extended by including the appropriate investment expenditure variable in each output equation. A number of alternative formulations was possible. Following the theoretical exposition in the previous section, we should, in principle, add three policy variables to each of the output equations in the VAR; indeed, we should add both investment and government expenditure variables for all three regions to each region's output equation. But this would increase the number of variables in each equation by six and consume already scarce degrees of freedom. Hence we compromised by, first of all, analysing the effects of investment and government expenditure separately and, then in each case, by adding only each region's own investment to its output equation. Hence, strictly speaking, we analyse a near-VAR rather than a VAR since each equation now has different regressors and, for this reason, OLS is not efficient as a systems estimator as it is for a standard VAR. Efficiency gains can be obtained by using a seemingly-unrelated regression (SUR) procedure which we use.

The estimated model is reported in Table 2.

\section{[Table 2 near here]}

The policy variable is significant and positive in each equation. The coefficient of investment is largest for the coastal region, followed by the central region and then the western region, although the differences are not large. Thus, a $10 \%$ increase in regional investment results in a contemporaneous increase of about $2.5 \%$ in the coastal region, of about $1.9 \%$ in the central region and approximately $1.7 \%$ in the western region. If these elasticities are converted to level effects using the sample averages of the ratios of investment to output, we obtain figures of $2.35,1.55$ and 0.98 for the coastal, central and western regions respectively meaning that a 1 yuan increase in investment expenditure by the government in the coastal region generates additional output within one year of 2.35 
yuan etc. Thus there is a multiplier effect within the year and this effect is stronger for the coastal region than it is for the other two regions. If we interpret this in a simple circular-flow framework, it suggests larger leakages from the circular flow in the central and western regions than in the coastal region.

The relative magnitudes of the contemporaneous effects are consistent with the view that even if the central government increases its expenditure in the poorer regions, much of the subsequent increase in output disappears (to the coastal region). However, such a conclusion would be premature since the individual coefficients show only part of the effects, viz., the contemporaneous effects. Moreover, they tell us nothing directly about spillover effects. Given the dynamic interdependences in the model, subsequent changes in output may strengthen or weaken the initial impact and spread the effect to other regions, i.e., the effect may spill over into other regions. Simulations taking account of all the model interactions are captured by the IRFs, which for a unit shock to coastal investment are pictured in Figure 1.

[Figures 1, 2, 3 near here]

The initial effect is restricted by the model to be on coastal output only since the coastal investment variable appears only in the equation for coastal output. The first-period effect on coastal output reflects the size of the investment coefficient of 0.24 in the coastal equation reported in Table 2. The effect on coastal output declines rapidly so that by period 3 it has become slightly negative. There is a spillover into the other regions but it is negative for both so that, far from a beneficial effect on the other regions, an increase in investment in the coastal region boosts coastal output at the expense of output in the other two regions.

Similar effects for shocks to investment in the central and western regions are reported in Figures 2 and 3. The IRFs for the boost to central investment show that the short-run effects are dominated by that on the central region itself. There is a subsequent positive spillover to the coastal region, although this effect is considerably smaller than the initial shock, but the spillover effect on the western region is negative as was the case with a coastal shock. Thus, while there are modest beneficial effects on the coastal region, the shock to central is at the expense of output in the western region. 
The effects of western shocks are an interesting contrast: although initially there is an expansion in output only in the western region, subsequent spillovers to the other two regions are both positive and relatively large, although the spillover to the contiguous central region is larger than it is for the more distant coastal region.

Thus, the spillover results generated by the IRF analysis reinforce the impressions gained from a comparison of the model coefficients: we found that a 1 yuan increase in regional investment expenditure has a larger contemporaneous effect in the coastal region than it does in the central region which in turn shows a larger effect than the western region. We argued that a possible explanation was the existence of greater leakages from the circular flow in the western region and, to a lesser extent, the central region than leakages from the coastal region. The subsequent flows through output appear to emphasise these effects - there are no positive spillovers from the coastal region to the other two, there are small positive spillovers from the central region to the coastal region but not to the western region and there are larger positive spillovers from the western region to the other two regions.

It is tempting to explain these effects in terms of the "backwash" and "spread" effects, concepts derived from an earlier economic development literature and which were briefly discussed in the introductory section. These results would then reflect the stage of Chinese development where the "core", particularly the coastal region, was still developing at the expense of the periphery and attempts to boost the latter region are dissipated. While we would not wish to make too much of this explanation, given that the model and econometric framework has not been set up to test this hypothesis, it is nevertheless suggestive.

Before drawing strong conclusions, it is important to point out that these results are in considerable contrast to the results reported in Groenewold et al. (2005a and 2006) for spillovers when output is shocked in a three-region VAR model. In Groenewold et al. (2005a) shocks to both coastal and central regions resulted in positive spillovers to the other two regions whereas the western region had effectively no spillovers to the rest of the country. These results were largely confirmed in subsequent work reported in Groenewold et al. (2006). Some of the difference in the current results is likely to be a function of model specification; in particular, the model used in the two papers just cited 
omits the policy variables and shocks output directly and the model in the first paper is subject to the problem of sensitivity to variable-ordering which is not a problem in present model. The ordering problem cannot be the whole of the explanation, however, since a version of the model including a correction for this problem in Groenewold et al. (2006) reports IRFs closer to the ones reported here but still with significant differences. The remaining differences must be brought home to the differences in model specification; in particular, the inclusion of the policy variables in this model not only provides policy variables to shock but also changes the mechanism through which these shocks are propagated through the system.

\subsection{Shocks to General Government Expenditure}

The second set of simulations we report are those to government expenditure. As in the previous exercise, we include the regional policy variable only in each region's own output equation. The resulting model is estimated using the SUR estimator. The estimated model is reported in Table 3.

\section{[Insert Table 3 near here]}

Clearly, the coefficient of the expenditure variable is positive and strongly significant in each case. The magnitude of each coefficient is similar to its counterpart in the previous model specification using investment. If the elasticities are converted to level effects the implied contemporaneous increases in output from a given yuan increase in government expenditure are similar to those generated by an increase in investment $(2.01,1.49$ and 1.02 for coastal, central and western regions respectively). Thus the two policy variables are about equally effective in the short run although investment expenditure has a small advantage in the coastal and central regions.

To gauge the effects of expenditure shocks which account for all the interactions in the model, we need to examine the IRFs. These are shown in Figures 4, 5, and 6.

\section{[Figures 4, 5, 6 near here]}

Here, too, the effects of an expenditure shock are broadly similar to those of an investment shock which is not surprising since the relative initial effects are the same, as we have seen, and the dynamic inter-relationships between regional output should not be 
greatly affected by substituting one exogenous variable for another. Thus the way in which the effects of the initial shocks is propagated through the system should not change too much from one shock to the other. There are some differences, however. Beginning with the effect of a coastal shock, its expansionary effect on the coastal region again comes at the expense of reductions in output in the other two regions although in the present case, the fall in western output is greater than it is in central output. In the case of a shock to central expenditure, there are now substantial negative spillovers to both other regions over the first five years. Finally, the effect of a boost to government expenditure in the western region again has short-term positive spillovers to the other two regions although they are more modest than in the case of investment, which may be explained by the greater difficulty of shifting general government expenditure from one region to another than it is for investment expenditure.

In conclusion we can say that the contemporaneous effects of both policy variables are positive in all three regions. The results are stronger in the coastal region than they are in the central region where they are, in turn, stronger than in the western region. This is true for both shocks. Comparing the two policy instruments, the investment shock produces a slightly larger increase in output than the government expenditure shock. Thus there appears some substance to the argument that a large part of the beneficial effects of increased expenditure in the inland regions flow out to the coastal region although this is more so for the western region than the central region.

When we take the whole model and its dynamic interrelationships into account, we find that an expansionary policy shock (of either type) in the coastal region comes at the expense of output in both the other regions and that, in contrast, an increase in either policy variable in the western region has positive spillovers to both other regions. The results for the central region are mixed - an investment expansion has a negative effect on western output but a small positive spillover to the coast while a government expenditure boost has adverse effects on both other regions.

\section{Conclusions}

This paper has analysed the effects on regional outputs in China of shocks to two policy variables - investment expenditure and general government expenditure. We 
conducted our analysis within the framework of a VAR and in doing so extended earlier work by Groenewold et al. (2005a, 2005b, 2006) by introducing policy variables explicitly into the model.

We found that both policy variables were significant in the output equations for each of the regions when entered separately and in all cases had a positive coefficient. In the short run both policy variables have a greater effect on the coastal region than on the other two and the effect in the central region was larger than in the western region, giving some credence to the common presumption that at least part of the expenditure boosts in the poorer inland regions find their way to the coastal provinces. These results are generally confirmed when we use the whole model to simulate the effects over time of the policy shocks. A shock to the coastal region not only has no beneficial spillovers to the other regions but actually depresses the output of the inland provinces. This is also true of a shock to the central region which comes at the expense of the western region. Only the western region has consistent positive spillovers on the other regions; looked at another way, a boost to the western region is shifted partially to the other regions.

We provided a tentative explanation in terms of the concepts of "backwash" and "spread effects used in an earlier literature on regional disparities in the growth process. In that explanation, the development of the Chinese economy is still at the stage where growth in the "core" is at the expense of the "periphery" so that expansions of the core (particularly the coastal region) are at the expense of the periphery while resources used to boost the periphery directly find their way to the core. While these are suggestive, we should add the caveat that our model was not designed to test this broad development hypothesis and our results should be seen as circumstantial at best. 
References:

Bao, S., G. H. Chang, J. D. Sachs and W. T. Woo (2002), "Geographic Factors and China's Regional Development under Market Reforms, 1978-1998”, China Economic Review, 13, 89-111.

Barro, R. J. and X. Sala-i-Martin (1992), “Convergence”, Journal of Political Economy, $100,223-251$.

Brun, J.F., J. L. Combes and M. F. Renard (2002), “Are there Spillover Effects between the Coastal and Noncoastal Regions in China?", China Economic Review, 13, pp. 161-169.

Cai, F., D. Wang and Y. Du (2002), "Regional Disparity and Economic Growth in China: The Impact of Labor Market Distortions", China Economic Review, 13, 197-212.

Carlino, G. and R. DeFina (1995), "Regional Income Dynamics", Journal of Urban Economics, 37, pp 88-106.

Chang, G. H. (2002), “The Cause and Cure of China's Widening Income Disparity", China Economic Review, 13, 335-340.

Chen, J. and B. M. Fleisher (1996), "Regional Inequality and Economic Growth in China", Journal of Comparative Economics, 22, 141-164.

Clark, T. E. (1998), "Employment Fluctuations in the U.S. Regions and Industries: The Roles of National, Region-Specific and Industry-Specific Shocks", Journal of Labor Economics, 16, 202-229.

Cromwell, A.B. (1992), "Does California Drive the West? An Econometric Investigation of Regional Spillovers", Federal Reserve Bank of San Francisco Economic Review, 2, pp.15-25.

Demurger, S. (2001), "Infrastructure Development and Economic Growth: An Explanation for Regional Disparities in China?", Journal of Comparative Economics, 29, 95-117.

Demurger, S., J. D. Sachs, W. T. Woo, S. Bao, G. Chang and A. Mellinger. (2002). "Geography, Economic Policy and Regional Development in China", NBER Working Paper 8897, April 2002.

Demurger, S., J. D. Sachs, W. T. Woo, S. Bao and G. Chang. (2002), "The Relative Contributions of Location and Preferential Policies in China's Regional 
Development: Being in the Right Place and Having the Right Incentives", China Economic Review, 13, 444-465.

Enders, W. (2004), Applied Econometric Time Series, second edition, Wiley.

Fleisher, B. M and J. Chen (1997), "The Coast-Noncoast Income Gap, Productivity and Regional Economic Policy in China", Journal of Comparative Economics, 25, 220-236.

Fu, X. (2004), "Limited Linkages from Growth Engines and Regional Disparities in China", Journal of Comparative Economics 32, 148-164.

Groenewold, N., G. Lee and A. Chen (2005a), "Regional Output Spillovers in China: Estimates from a VAR Model”, Discussion Paper No. 05-05, Department of Economics, University of Western Australia. Available at: http://www.ecom.uwa.edu.au/information_about/research/discussion_papersworki $\underline{\text { ng documents/economics }}$

Groenewold, N., G. Lee and A. Chen (2005b), "Inter-Regional Spillovers in China: The Importance of Common Shocks and the Definition of the Regions", Discussion Paper No. 05-19, Department of Economics, University of Western Australia. Available at: http://www.ecom.uwa.edu.au/_data/page/64357/05_19_Groenewold.pdf

Groenewold, N., G. Lee and A. Chen (2006), "Inter-Regional Output Spillovers", Chapter 3 in Y. Wu (ed.), Economic Transition, Growth and Globalization in China, Edward Elgar, Cheltenham, UK, 61-81.

Hirschman, A. (1958) The Strategy of Economic Development, Yale University Press, New Haven.

Kanbur, R. and X. Zhang (1999), "Which Regional Inequality? The Evolution of RuralUrban and Inland-Coastal Inequality in China from 1983 to 1995”, Journal of Comparative Economics, 27, 686-701.

Kouparitsas, M. A. (2002), "Understanding US Regional Cyclical Comovement: How Important Are Spillovers and Common Shocks?", Federal Reserve Bank of Chicago Economic Perspectives, $4^{\text {th }}$ quarter, 30-41.

Krugman, P. (1991a), Geography and Trade, MIT Press, Cambridge MA. 
Krugman, P. (1991b), "Increasing Returns and Economic Geography", Journal of Political Economy, 99, 483-499.

Krugman, P. and A. Venables (1995), "Globalisation and the Inequality of Nations", Quarterly Journal of Economics, 110, 857-879.

Kuznets, S. (1955), "Economic Growth and Income Inequality", American Economic Review, 45, 1-28.

Lu, D. (2002), "Rural-Urban Income Disparity: Impact of Growth, Allocative Efficiency and Local Growth Welfare", China Economic Review, 13, 419-429.

Myrdal, G. (1957), Economic Theory and Underdeveloped Regions, Gerald Duckworth, Essex.

Puga, D. (1999), “The Rise and Fall of Regional Inequalities", European Economic Review 43, 303-334.

Rissman, E. R, (1999), "Regional Employment Growth and the Business Cycle”, Federal Reserve Bank of Chicago Economic Perspectives, $4^{\text {th }}$ quarter, 21-39.

Sherwood-Call, C. (1988), "Exploring the Relationship between National and Economic Fluctuations", Federal Reserve Bank of San Francisco Economic Review, Summer, $15-25$.

State Statistical Bureau (1997), Data and Materials on China's Capital Construction 1950-1995, Statistical Publishing House of China, Beijing.

State Statistical Bureau (2000), Comprehensive Statistical Data and Materials on 50 Years of New China, Statistical Publishing House of China, Beijing.

State Statistical Bureau (various issues), China Statistical Abstract, Statistical Publishing House of China, Beijing.

State Statistical Bureau (various issues), Statistical Yearbook of China, Statistical Publishing House of China, Beijing.

Williamson, J. (1965), "Regional Inequality in the Process of National Development", Economic Development and Cultural Change, 17, 3-84.

Wu, Y. (2004), China's Economic Growth: A Miracle with Chinese Characteristics, London: Routledge Curzon.

Yang, D. T. (2002), “What Has Caused Regional Inequality in China?”, China Economic Review, 13, 331-334. 
Yao. S. and Z. Zhang (2001a), "Regional Growth in China Under Economic Reforms", Journal of Development Studies, 38, 167-186.

Yao, S. and Z. Zhang (2001b), "On Regional Inequality and Diverging Clubs: A Case Study of Contemporary China”, Journal of Comparative Economics, 29, 466-484.

Ying, L. G. (2000), “Measuring the Spillover Effects: Some Chinese Evidence”, Papers in Regional Science, 79, pp. 75-89.

Zhang Q. and B. Felmingham (2002), "The Role of FDI, Exports and Spillover Effects in the Regional Development of China", Journal of Development Studies, 38, 157- 178. 
Table 1. Stationary Tests for (logs of) Real Output, Government Investment Expenditure and General Government Expenditure

\begin{tabular}{cllllll}
\hline \multirow{2}{*}{ Region } & \multirow{2}{*}{ No break } & & \multicolumn{3}{c}{ One break in trend } & \multicolumn{2}{l}{$\begin{array}{l}\text { One break in } \\
\text { level and trend }\end{array}$} \\
\cline { 5 - 7 } & & & 1966 & 1978 & 1966 & 1978 \\
\hline Lco & -1.45 & -1.61 & $-4.47^{* *}$ & -1.74 & $-4.42^{* *}$ \\
Lce & -1.21 & -2.97 & $-4.64^{* * *}$ & $-4.26^{* *}$ & $-7.15^{* * *}$ \\
Lwe & -1.88 & -3.52 & $-3.75^{*}$ & $-5.96^{* * *}$ & $-4.08^{*}$ \\
Invco & -1.90 & $-5.65^{* * *}$ & $-3.96^{* *}$ & $-5.53^{* * *}$ & -3.92 \\
Invce & -1.43 & -3.17 & $-4.34^{* *}$ & -2.82 & $-4.36^{* *}$ \\
Invwe & $-4.05^{* *}$ & $-4.45^{* *}$ & $-5.01^{* * *}$ & $-4.38^{* *}$ & $-5.60^{* * *}$ \\
Expco & $-3.25^{*}$ & $-3.88^{*}$ & $-3.91^{*}$ & -3.84 & $-4.04^{*}$ \\
Expce & $-3.58^{* *}$ & $-3.89^{*}$ & $-4.27^{* *}$ & -3.83 & $-4.18^{*}$ \\
Expwe & $-4.41^{* * *}$ & $-4.77^{* * *}$ & $-4.59^{* * *}$ & $-4.72^{* *}$ & $-4.54^{* *}$ \\
\hline
\end{tabular}

A “***" indicates significance at $1 \%$, a "***" at $5 \%$ and a "**” at $10 \%$ for the ADF test.

Lco, Lce and Lwe are the logs of real GDP for the coastal, central and western region respectively; .Invco, Invce, Invwe are the logs of government investment expenditure for the coastal, central and western region respectively; Expco, Expce, Expwe are the logs of general government expenditure for the coastal, central and western region respectively. The first three lines of ADF statistics are taken from Groenewold et al. (2005a). 
Table 2: Estimated Model with Government Investment Expenditure

\begin{tabular}{|c|c|c|c|c|c|c|}
\hline \multirow{2}{*}{ Regressor } & \multicolumn{2}{|c|}{ Coastal } & \multicolumn{2}{|c|}{ Central } & \multicolumn{2}{|c|}{ Western } \\
\hline & Coefficient & t-stat & Coefficient & t-stat & Coefficient & t-stat \\
\hline $\operatorname{Lco}(-1)$ & 0.0513 & 0.27 & -0.4169 & -1.96 & -0.1523 & -0.69 \\
\hline $\mathrm{Lco}(-2)$ & 0.0098 & 0.06 & -0.0457 & -0.24 & -0.2318 & -1.16 \\
\hline $\operatorname{Lce}(-1)$ & 0.1441 & 0.65 & 0.3520 & 1.35 & -0.3644 & -1.34 \\
\hline $\operatorname{Lce}(-2)$ & -0.0574 & -0.28 & 0.0393 & 0.17 & 0.1342 & 0.55 \\
\hline Lwe(-1) & 0.1078 & 0.87 & 0.4375 & 3.09 & 0.7027 & 4.83 \\
\hline Lwe(-2) & -0.0974 & -0.81 & -0.1080 & -0.79 & -0.0443 & -0.31 \\
\hline Constant & 2.7885 & 14.46 & 2.6012 & 11.84 & 2.9739 & 12.57 \\
\hline Trend & 0.0317 & 9.44 & 0.0258 & 6.97 & 0.0209 & 5.68 \\
\hline DU1 & 0.0783 & 2.59 & 0.0486 & 1.47 & -0.1045 & -3.13 \\
\hline DU2 & -0.0035 & -0.12 & 0.0074 & 0.24 & 0.0257 & 0.78 \\
\hline DT1 & -0.0045 & -0.70 & 0.0044 & 0.63 & 0.0436 & 7.06 \\
\hline DT2 & 0.0362 & 8.70 & 0.0270 & 6.33 & 0.0099 & 2.31 \\
\hline Invco & 0.2498 & 11.30 & & & & \\
\hline Invce & & & 0.1891 & 8.78 & & \\
\hline Invwe & & & & & 0.1716 & 8.09 \\
\hline $\bar{R}^{2}$ & 0.9991 & & 0.9983 & & 0.9984 & \\
\hline
\end{tabular}

Lco, Lce and Lwe are the logs of real GDP for the coastal, central and western region respectively. Invco, Invce, Invwe are the logs of government investment expenditure for the coastal, central and western region respectively. The deterministic variables, in addition to the trend, are DU1, DU2 which are the level breaks at 1966 and 1978 and DT1 and DT2 which are the corresponding trend breaks. 
Table 3: Estimated Model with General Government Expenditure

\begin{tabular}{|c|c|c|c|c|c|c|}
\hline \multirow{2}{*}{ Regressor } & \multicolumn{2}{|c|}{ Coastal } & \multicolumn{2}{|l|}{ Central } & \multicolumn{2}{|c|}{ Western } \\
\hline & Coefficient & t-stat & Coefficient & t-stat & Coefficient & t-stat \\
\hline $\mathrm{Lco}(-1)$ & 0.6126 & 2.14 & 0.0242 & 0.08 & 0.1713 & 0.59 \\
\hline $\operatorname{Lco}(-2)$ & -0.2751 & -1.08 & 0.0233 & 0.08 & -0.1950 & -0.75 \\
\hline $\operatorname{Lce}(-1)$ & -0.1554 & -0.43 & 0.1673 & 0.42 & -0.4416 & -1.19 \\
\hline $\operatorname{Lce}(-2)$ & -0.3409 & -1.09 & -0.4327 & -1.26 & -0.2342 & -0.73 \\
\hline Lwe(-1) & 0.0688 & 0.37 & 0.3356 & 1.65 & 0.6837 & 3.64 \\
\hline Lwe(-2) & 0.1455 & 0.79 & -0.0375 & -0.19 & -0.0903 & -0.48 \\
\hline Constant & 3.2867 & 9.96 & 2.9970 & 8.48 & 3.2837 & 9.29 \\
\hline Trend & 0.0163 & 3.48 & 0.0154 & 3.03 & 0.0188 & 3.97 \\
\hline DU1 & 0.1026 & 2.08 & 0.0973 & 1.87 & 0.0113 & 0.23 \\
\hline DU2 & -0.0074 & -0.17 & 0.0070 & 0.15 & 0.0111 & 0.26 \\
\hline DT1 & 0.0229 & 2.78 & 0.0146 & 1.62 & 0.0350 & 4.16 \\
\hline DT2 & 0.0364 & 5.41 & 0.0394 & 5.30 & 0.0332 & 4.50 \\
\hline Expco & 0.2152 & 6.03 & & & & \\
\hline Expce & & & 0.1969 & 5.11 & & \\
\hline Expwe & & & & & 0.1728 & 4.73 \\
\hline $\bar{R}^{2}$ & 0.9980 & & 0.9968 & & 0.9974 & \\
\hline
\end{tabular}

Lco, Lce and Lwe are the logs of real GDP for the coastal, central and western region respectively. Expco, Expce, Expwe are the logs of general government expenditure for the coastal, central and western region respectively. The deterministic variables, in addition to the trend, are DU1, DU2 which are the level breaks at 1966 and 1978 and DT1 and DT2 which are the corresponding trend breaks. 
Fig. 1. The effects of a shocks to coastal investment

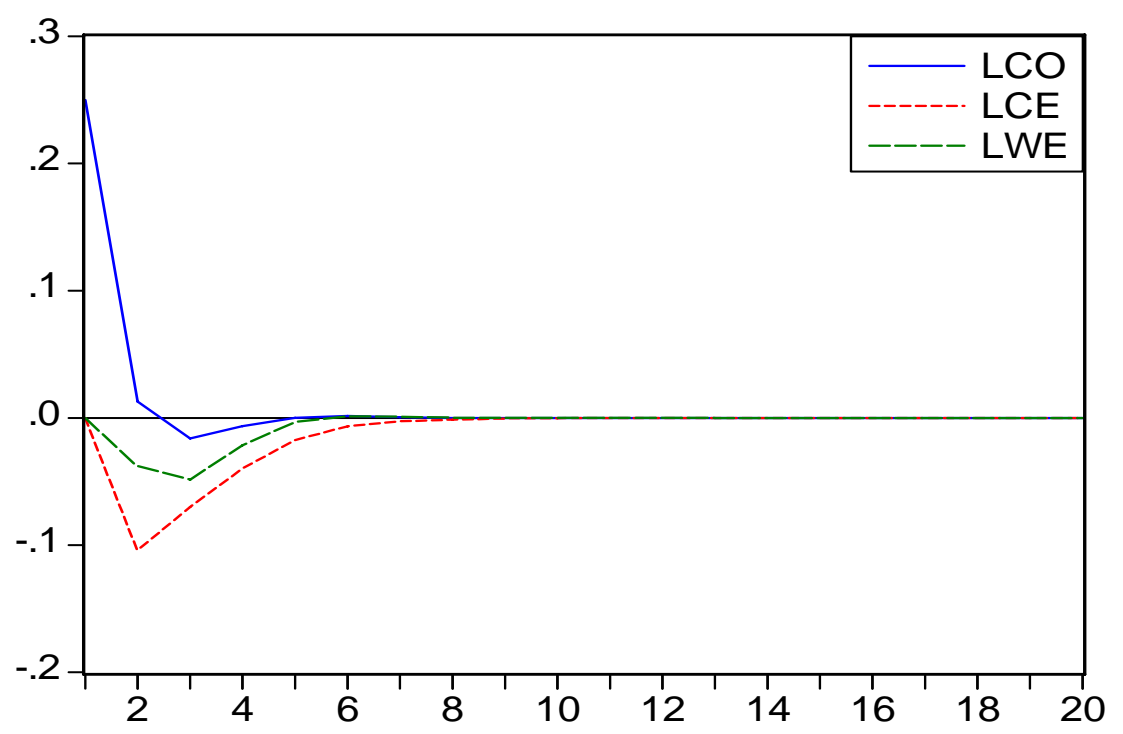

Fig. 2 The effects of a shock to central investment

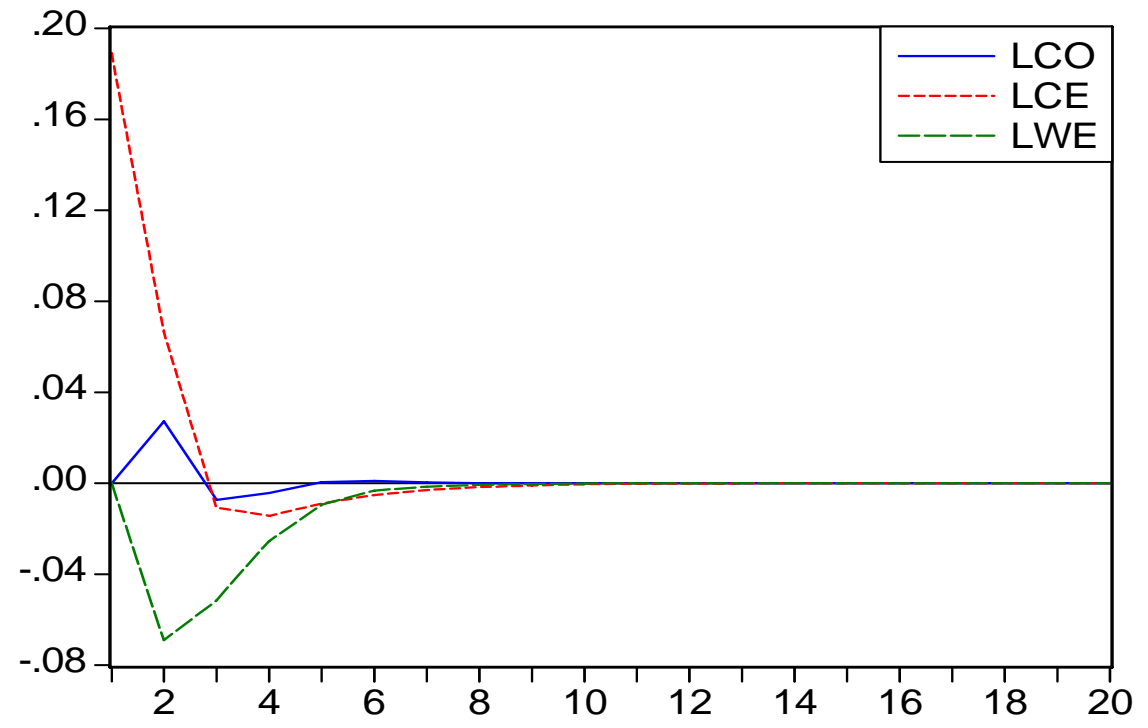


Fig. 3 The effects of a shock to western investment

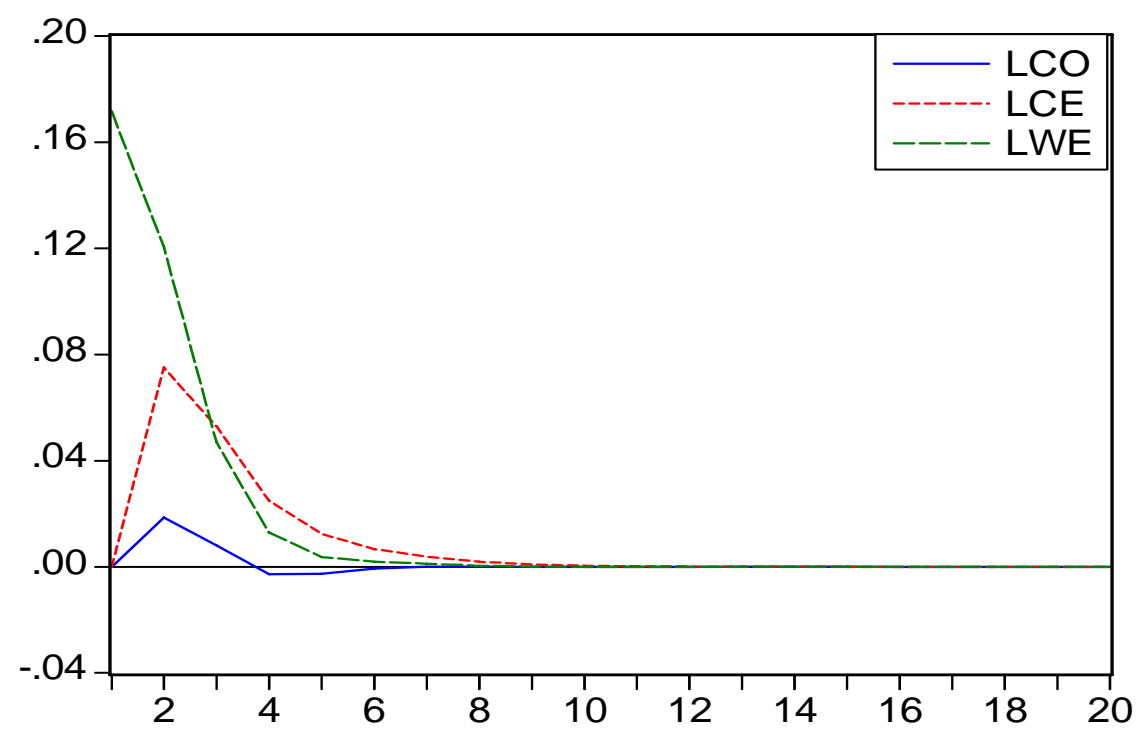

Fig. 4. The effects of a shock to coastal expenditure

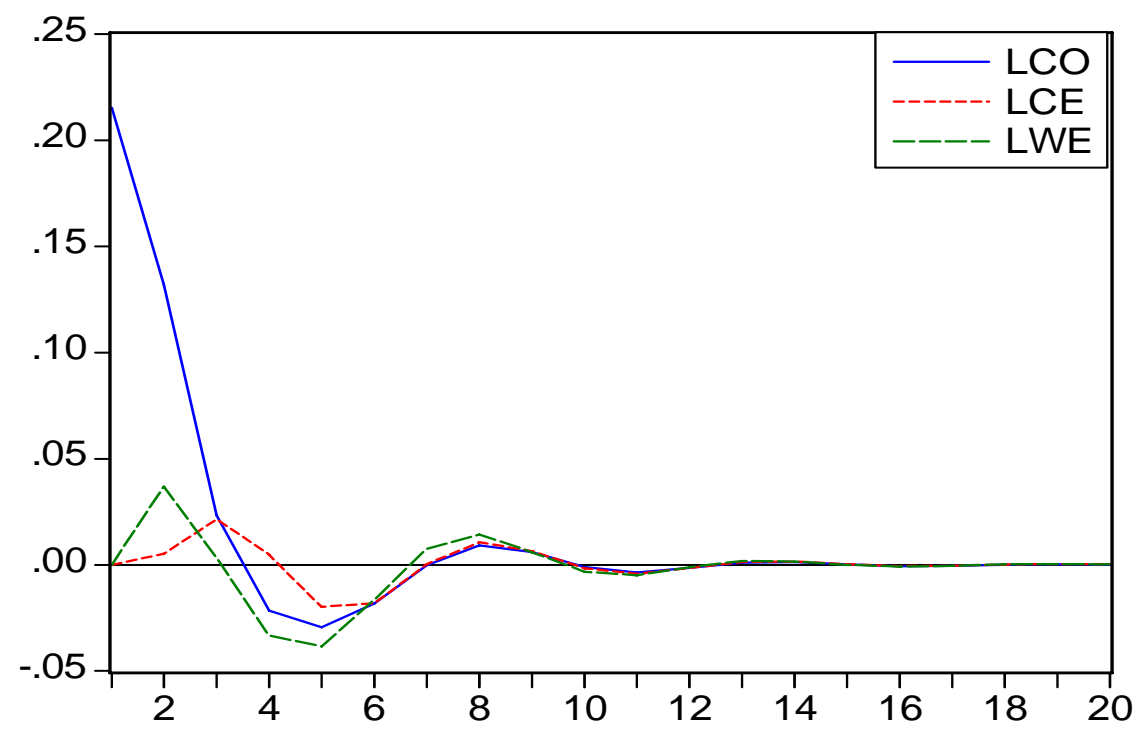


Fig. 5. The effects of a shock to central expenditure

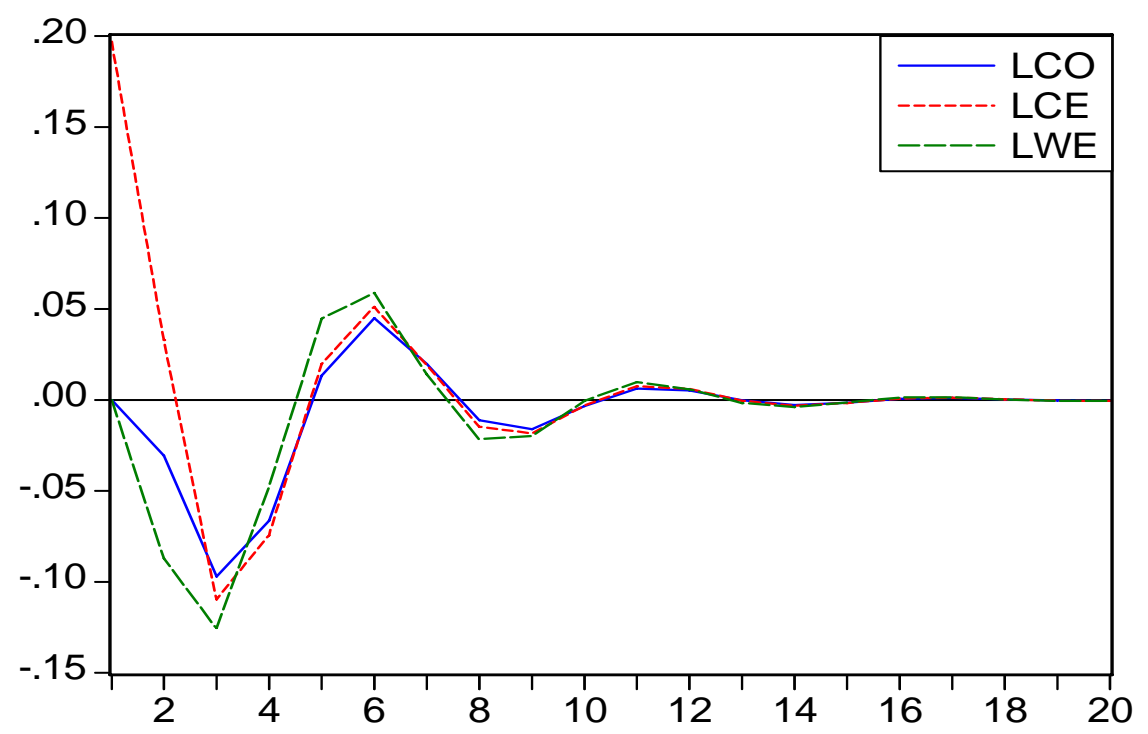

Fig. 6. The effects of a shock to western expenditure



${ }^{1}$ Per capita GDP data from China Statistical Abstract, 2006.

${ }^{2}$ For a more extensive discussion of the regional implications of the various Five-Year Plans, see Groenewold et al. (2005b).

${ }^{3}$ The literature goes back at least to the work of Kuznets (1955) and Williamson (1965); the concept was more recently developed in Barro and Sala-i-Martin (1992). There is a vast empirical literature. Some 
important papers with a bias to Chinese applications are: Chen and Fleisher (1996), Fleisher and Chen (1997), Kanbur and Zhang (1999), Yao and Zhang (2001a, 2001b), Demurger (2001), Chang (2002), Lu (2002), Cai, Wang and Du (2002), Yang (2002), Demurger, Sachs, Woo, Bao, Chang and Mellinger (2002), Bao, Chang, Sachs and Woo (2002) and Demurger, Sachs, Woo, Bao and Chang (2002).

${ }^{4}$ A set of papers using a modelling approach similar to the one used in Groenewold et al. (2005a, 2005b, 2006) applied to the US are Sherwood-Call (1988), Cromwell (1992), Carlino and DeFina (1995), Clark (1998), Rissman (1999) and Kouparitsas (2002).

${ }^{5}$ Since beginning this project, the 2004 data have become available. We have not updated our data set in the interests of preserving comparability with the results reported in Groenewold et al. (2005a, 2005b, 2006) whose sample period stops at 2003

${ }^{6}$ For government investment we use data for "investment in capital construction". This was all publiclyfinanced in the first half of the sample but more recently includes privately-financed investment expenditure. We use this to ensure reasonable continuity in the series even though an increasing component of it is not, strictly-speaking, a policy variable. While this means that the variable is not strictly exogenous, it should be recognised that the central government continues to have extensive control of investment through, for example, directed lending by major banks which is still a major source of funds for "private" investment.

${ }^{7}$ Note that Hainan, Chongqing and Tibet are missing. Hainan is included in Guangdong and Chongqing in Sichuan. Tibet has been omitted altogether due to missing data.

${ }^{8}$ Generally independence of the $e_{i}$ terms is not guaranteed by theoretical restrictions nor supported by the data and must be imposed by transforming them to ensure orthogonality. The standard method for achieving orthogonality is based on the use of the Choleski orthogonalisation of the covariance matrix of the errors and this procedure makes the IRFs dependent on the order in which the variables are entered into the model although the issue is not serious in applications where the correlation of the errors is weak. For an extensive discussion of this issue in a bivariate context, see Ender (2004), Chapter 5. 